Review Article

\title{
Deep brain stimulation for psychiatric disorders: Is there an impact on social functioning?
}

\author{
Christian Saleh, Gregor Hasler \\ Division of Molecular Psychiatry, Translational Research Center, University Hospital of Psychiatry and Psychotherapy, University of Bern, Bern, Switzerland \\ E-mail: *Christian Saleh - chs12us75010@yahoo.com; Gregor Hasler - gregor.hasler@puk.unibe.ch \\ *Corresponding author \\ Received:09 January 17 Accepted: 06 May $17 \quad$ Published: 07 July 17
}

\begin{abstract}
Background: Deep brain stimulation (DBS) for refractory psychiatric disorders shows promising effects on symptom-reduction, however, little is known regarding the effects of DBS on social outcome.

Methods: A PubMed search based on original studies of DBS for psychiatric disorders [treatment resistant depression (TRD), Gilles de la Tourette's syndrome (GTS), and obsessive compulsive disorder (OCD)] was conducted. Data on social outcome following surgery were extracted and analyzed.

Results: Social functioning was not a primary outcome measure in the reviewed article. The literature is incomplete and inconclusive on this variable, however from the reported data, there is some evidence that DBS has the potential to improve social functioning.

Conclusions: More systematic and detailed data gathering and reporting on social outcome with longer follow-ups are needed to evaluate more exhaustively the role of DBS in refractory psychiatric disorders.

Key Words: Deep brain stimulation, Gilles de la Tourette's syndrome, obsessive compulsive disorder, refractory psychiatric disorders, social outcome, treatment resistant depression

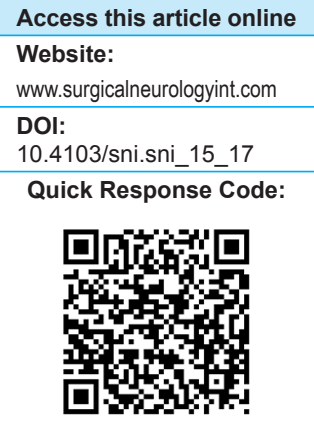

\section{INTRODUCTION}

Deep brain stimulation (DBS) is considered a safe and established treatment option with the advantages of being nondestructive, reversible, and adjustable. The renaissance of DBS dates to 1987, when the French group led by Benabid applied DBS for refractory motor disease, ${ }^{[3]}$ while the end of the 1990s saw the first applications of DBS for refractory psychiatric disorders. In 1999, the pioneering papers on DBS for refractory Gilles de la Tourette's syndrome (GTS) and obsessive compulsive disorders (OCD) were published, respectively, by the Dutch group led by Vandewalle ${ }^{[42]}$ and by the Belgian group of Nuttin et al. ${ }^{[24]}$ Six years later appeared the work of the US-Canadian team of
Mayberg and Lozano for DBS in refractory depression. ${ }^{[23]}$ Since then, multiple smaller open studies were published showing promising results with an overall response rate of 30-50\%. ${ }^{[35]}$ Much focus in the evaluation of the effectivity of DBS is placed on the reduction of symptoms, whereas

This is an open access article distributed under the terms of the Creative Commons Attribution-NonCommercial-ShareAlike 3.0 License, which allows others to remix, tweak, and build upon the work non-commercially, as long as the author is credited and the new creations are licensed under the identical terms.

For reprints contact: reprints@medknow.com

How to cite this article: Saleh C, Hasler G. Deep brain stimulation for psychiatric disorders: Is there an impact on social functioning?. Surg Neurol Int 2017;8:134. http://surgicalneurologyint.com/Deep-brain-stimulation-for-psychiatric-disorders:-Isthere-an-impact-on-social-functioning?/ 
little is known as to the social impact of DBS for psychiatric disorders. Social functioning is a key outcome in young patients with neurodevelopmental psychiatric condition. ${ }^{[7,27,37]}$ The improvement of social skills and functioning is crucial for the long-term outcome of psychiatric disorders with an early age of onset. Social integration and social support belong to the strongest correlates of a healthy psychological development. Even psychotherapy trials show that psychosocial interventions results in only small to moderate improvements in social outcomes, and that these improvements are associated with, but not fully explained by symptom reduction. ${ }^{[32]}$ There is no review paper investigating the relation DBS in refractory psychiatric disorders and social functioning. With this study, we aimed therefore at elucidating the effects on social functioning of DBS for psychiatric disorders.

\section{MATERIALS AND METHODS}

A PubMed search based on original studies of DBS for psychiatric disorders was conducted without any time limit. Only articles in English language were selected. The search was based on the current three main DBS indications for refractory psychiatric disorders, treatment resistant depression (TRD), GTS, and OCD. Key words used were "deep brain stimulation" in combined fashion with "Gilles de la Tourette's syndrome," "obsessive compulsive disorder," and "depression." Only original studies, case reports/case series were included. Reviews, commentaries and basic research studies were excluded. Further articles were identified via an analysis of relevant papers obtained from the first literature search. From the initial search, we considered 87 papers for the first analysis. All papers on DBS for psychiatric disorders were reviewed at this stage for the outcome measure of social functioning; only articles reporting on this variable were considered for final analysis. Thirty two articles were included for our study: 11 GTS studies, 13 OCD studies, and 8 TRD studies. For each psychiatric indication, the data on demographics, the clinical results of DBS and the effect on social behavior were extracted, tabulated, and analyzed [Tables 1-3]. The data related to social behavior was reported quantitatively or qualitatively. Studies that

Table 1: Deep brain stimulation in Gilles de la Tourette syndrome

\begin{tabular}{|c|c|c|c|c|c|c|c|c|c|c|}
\hline Authors (Year) & $\begin{array}{l}\text { Sample } \\
\text { Size }\end{array}$ & $\begin{array}{l}\text { Gender } \\
(\mathbf{f}, \mathbf{m})\end{array}$ & Age (y) & $\begin{array}{c}\text { Disease } \\
\text { duration (y) }\end{array}$ & Comorbidities & FU (m) & $\begin{array}{l}\text { YGTSS - \% } \\
\text { reduction }\end{array}$ & $\begin{array}{l}\text { YBOCS: \% } \\
\text { change }\end{array}$ & $\begin{array}{l}\text { Social function } \\
\text { (Scale) }\end{array}$ & Reference \\
\hline Sachdev (2014) & 17 & 3,14 & 29 & NM & NM & 24 & 45 & $\mathrm{~N} / \mathrm{A}$ & $\begin{array}{l}\text { GAF: Pre-DBS: 50, } \\
\text { Post-DBS: } 72\end{array}$ & [34] \\
\hline Porta (2009) & 15 & 3,12 & 30 & FU & NM & 24 & 51.9 & 46.4 & $\begin{array}{l}\text { SSI-VAS mean pre/ } \\
\text { post: } 8.4 / 5.8\end{array}$ & [29] \\
\hline Cannon (2012) & 11 & 3,8 & 33 & 23 & $\begin{array}{l}\text { 1. SIB } \\
\text { 2. Coprolalia } \\
\text { 3. OCD } \\
\text { 4. Anxiety }\end{array}$ & 3 & 48.8 & 56.2 & $\begin{array}{l}\text { GAF: Pre-DBS: } 47, \\
\text { post-DBS: } 75\end{array}$ & [5] \\
\hline Huys (2016) & 8 & 5 & 33 & NM & $\mathrm{OCD}$ & 12 & 51 & $\begin{array}{l}\text { No significant } \\
\text { effect }\end{array}$ & $\begin{array}{l}\text { GAF: Pre-DBS: } 66, \\
\text { post-DBS: } 74\end{array}$ & [15] \\
\hline Dehning (2012) & 6 & 3,3 & 34 & 27.5 & NM & 32 & $\begin{array}{l}4 \text { responders } \\
\text { ( } 2 \text { nonresponders) }\end{array}$ & $\mathrm{N} / \mathrm{A}$ & $\begin{array}{l}\text { GAF: Pre-DBS: } 54, \\
\text { post-DBS: } 84\end{array}$ & [8] \\
\hline Kaido (2010) & 3 & 2,1 & 20 & 8.6 & NM & 12 & 36.1 & 0.0 & $\begin{array}{l}\text { YGTSS, pre-/ } \\
\text { post-DBS (part 3): } \\
\text { Pt 1: } 50 / 30 \\
\text { Pt 2: } 30 / 20 \\
\text { Pt 3: } 40 / 20\end{array}$ & [10] \\
\hline Servello (2009) & 4 & 1,3 & 35 & NM & OCD & 13 & 64.6 & 30.3 & NM & [39] \\
\hline Welter (2008) & 3 & 2,1 & 32 & 23.3 & $\begin{array}{l}\text { 1. MDD, SIB, } \\
\text { BPD } \\
\text { 2. GAD }\end{array}$ & 60 & $\begin{array}{l}\text { TA: } 64,30,40 \\
\text { Gpi: } 65,96,74 \\
\text { TA+Gpi: 60, } \\
43,76\end{array}$ & $\mathrm{~N} / \mathrm{A}$ & NM & [44] \\
\hline Shahed (2007) & 1 & 0,1 & 16 & 13 & $\begin{array}{l}\text { 1. OCD } \\
\text { 2. ADHD } \\
\text { 3. Coprolalia } \\
\text { 4. Depression }\end{array}$ & 4 & 76.0 & 69.9 & NM & [40] \\
\hline Lee (2011) & 1 & 0,1 & 31 & 24 & No & 18 & 58.0 & $\mathrm{~N} / \mathrm{A}$ & NM & [19] \\
\hline Zekaj (2015) & 1 & 0,1 & 17 & 10 & ADHD & 96 & $95 \%$ & NM & NM & [45] \\
\hline
\end{tabular}

GTS: Gilles de la Tourette syndrome, m: male, f: female, NM: Not Mentioned, OCD: Obsessive Compulsive Disorder, SIB: Self-Injury Behaviour, BPD: Borderline Personality Disorder,TA:Thalamus, Gpi: Globus pallidus internus, N/A: Not applicable,ADHD:Attention Deficit Hyperactivity Disorder, PT: Patient, YGTSS:Yale Global Tic Severity Scale, YBOCS:Yale Brown Obsessive Scale 
Table 2: Deep brain stimulation in obsessive compulsive disorder

\begin{tabular}{|c|c|c|c|c|c|c|c|c|c|c|}
\hline Authors (Year) & $\begin{array}{c}\text { Sample } \\
\text { Size }\end{array}$ & $\begin{array}{c}\text { Gender } \\
(\mathrm{f}, \mathrm{m})\end{array}$ & $\begin{array}{l}\text { Age } \\
\text { (y) }\end{array}$ & $\begin{array}{c}\text { Disease } \\
\text { Duration } \\
\text { (y) }\end{array}$ & Comorbidities & $\begin{array}{l}\text { Follow-up } \\
\text { (max., in } \\
\text { months) }\end{array}$ & $\begin{array}{l}1^{\circ} \text { Outcome } \\
\text { scale } \\
\text { (Y-BOCS) }\end{array}$ & $\begin{array}{c}\% \text { change } \\
\text { (at latest } \\
\text { follow-up)/ } \\
\text { mean (SD) } \\
>1 \text { pts }\end{array}$ & $\begin{array}{l}\text { Social function } \\
\text { (Scale) }\end{array}$ & References \\
\hline Mallet (2008) & 17 & 7,10 & 43 & 18 & NM & 10 & Y-BOCS & 36 & $\begin{array}{l}\text { GAF: Baseline 39, } \\
\text { End of On period: } 52\end{array}$ & [21] \\
\hline Ooms (2014) & 16 & 7,9 & 45 & 26 & NM & 12 & Y-BOCS & 41 & $\begin{array}{l}\text { GAF No significant } \\
\text { change }\end{array}$ & [26] \\
\hline Denys (2010) & 16 & 7,9 & 42.5 & 28.3 & $\begin{array}{l}\text { 1. MDD } \\
\text { 2. Mild anxiety }\end{array}$ & 12 & Y-BOCS & 46 & $\begin{array}{l}\text { Sheehan Disability } \\
\text { Scale: Improved }\end{array}$ & [9] \\
\hline Huff (2010) & 10 & 4,10 & 36.3 & 22.2 & NM & 12 & Y-BOCS & 31.2 & $\begin{array}{l}\text { GAF mean pre-DBS: } \\
\text { 36.6, mean } \\
\text { post-DBS: } 53.1\end{array}$ & [14] \\
\hline Greenberg (2006) & 10 & 4,6 & 35.3 & 22.5 & MDD & 36 & Y-BOCS & 35 & $\begin{array}{l}\text { GAF: Pre-DBS: } 36.6 \text {; } \\
\text { post-DBS: } 53.8\end{array}$ & [12] \\
\hline Tsai (2012) & 4 & 0,4 & 25.5 & 8.3 & MDD & 15 & Y-BOCS & 33 & $\begin{array}{l}\text { GAF: Pre-DBS: } 43.5, \\
\text { Post-DBS } 57.0\end{array}$ & [41] \\
\hline Chabardès (2012) & 4 & 2,2 & 38.2 & 20.5 & NM & 6 & Y-BOCS & 64.5 & $\begin{array}{l}\text { GAF mean pre-DBS: } \\
\text { 33.5; mean } \\
\text { post-DBS: } 72\end{array}$ & {$[6]$} \\
\hline Roh (2012) & 4 & 1,3 & 33.7 & 16.8 & MDD & 24 & Y-BOCS & 59.4 & $\begin{array}{l}\text { GAF: Mean pre-DBS: } \\
44.0\end{array}$ & [33] \\
\hline Servello (2009) & 4 & 1,3 & 35 & NM & GTS & 51 & Y-BOCS & 36 & $\begin{array}{l}\text { VAS: Baseline: 10.0, } \\
\text { last FU: } 7.0\end{array}$ & [39] \\
\hline Abelson (2004) & 4 & 2,2 & 40.2 & 22.5 & $\begin{array}{l}\text { 1. MDD } \\
\text { 2. Social phobia } \\
\text { 3. Tic disorder } \\
\text { 4. BDD } \\
\text { 5. Anorexia/ } \\
\text { Bulimia }\end{array}$ & 23 & Y-BOCS & 32.7 & $\begin{array}{l}\text { GAF mean pre-DBS: } \\
31.7 \text {, mean } \\
\text { post-DBS: } 52.5\end{array}$ & [1] \\
\hline Franzini (2010) & 2 & 0,2 & 37 & 21 & $\begin{array}{l}\text { 1. BP } \\
\text { 2. } B D D \\
\text { 3. Phobic anxiety } \\
\text { 4. MDD }\end{array}$ & 27 & Y-BOCS & 37.5 & $\begin{array}{l}\text { GAF: Pt } 1 \text { pre-DBS: } \\
\text { 40, post-DBS: } 60 ; \\
\text { Pt } 2 \text { pre-DBS: } 40 \text {, } \\
\text { post-DBS: } 60\end{array}$ & [10] \\
\hline Aquizerate (2004) & 1 & 1 & 56 & 40 & MDD & 15 & Y-BOCS & 44.0 & $\begin{array}{l}\text { GAF: Pre DBS: } 35, \\
\text { post- DBS: } 60\end{array}$ & [2] \\
\hline Jiménez (2013) & 6 & NM & 34.6 & 16 & $\begin{array}{l}\text { 1. Drug addiction } \\
\text { 2. Schizoid PD }\end{array}$ & 12 & Y-BOCS & 51 & NM & [17] \\
\hline
\end{tabular}

m: male, f: female, NM: Not Mentioned, DBS: Deep brain stimulation, GTS: Gilles de la Tourette's syndrome, GAF: Global Assessment of Functioning, FU: Follow-up, m: months, y: years, MDD: Major depressive disorder, BDD: Body dysmorphic disorder,YBOCS:Yale Brown Obsessive Compulsive Severity Scale,VAS:Visual analog scale

reported quantitative data as to social functioning are listed in the tables first, followed by studies that did not provide the data as to social functioning. Qualitative data in form of comments of the authors we reported verbatim. For each group the mean values for age, disease duration, sample-size, and follow-up period with standard deviation (SD) were calculated. The precise degree of overlap of cohorts reported in serial papers was not always specified. Therefore, for the reported mean values only approximations could be indicated. Studies are tabulated in order of decreasing sample size. The analyzed findings were organized in the results section. Studies that reported in more detail on social behavior were presented in a separate section "DBS and social behavior" classified equally into the three main psychiatric indications and listed in the same order as tabulated.

\section{RESULTS}

The studies included in our analysis included 236 patients: 70 GTS patients, 88 OCD patients, and 78 TRD patients [Tables 1-3]. Considering the great heterogeneity of data reporting, the small sample sizes, methodological limitations, the absence of control groups, an exhaustive and balanced comparison, and evaluation of the effects of DBS on social function remained challenging. The literature remained inconclusive in predicting the social outcome following DBS. Different scales in evaluating social impact 
Table 3: Deep brain stimulation in treatment refractory depression

\begin{tabular}{|c|c|c|c|c|c|c|c|c|c|}
\hline Authors (Year) & $\begin{array}{c}\text { Sample } \\
\text { Size }\end{array}$ & $\begin{array}{c}\text { Gender } \\
(\mathbf{f}, \mathbf{m})\end{array}$ & $\begin{array}{c}\text { Age } \\
\text { (y) }\end{array}$ & $\begin{array}{l}\text { Disease } \\
\text { Duration } \\
\text { (y) }\end{array}$ & Comorbidities & $\begin{array}{l}\text { FU } \\
\text { (m) }\end{array}$ & $\begin{array}{l}\text { Response/remission } \\
\text { (at latest follow-up) }\end{array}$ & Social function (Scale) & References \\
\hline Kennedy $(2011)^{*}$ & 20 & FU & FU & FU & FU & 36,72 & $\begin{array}{l}64.3 \% \\
\text { response/42.9\% } \\
\text { remission }\end{array}$ & SF-36: Pre-DBS: 48, Post-DBS: 71 & [18] \\
\hline Lozano (2008) & 20 & 11,9 & 47.4 & 20.3 & No & 12 & $\begin{array}{l}55 \% \text { response } / 35 \% \\
\text { remission }\end{array}$ & $\begin{array}{l}\text { Unemployment pre-DBS: } 18 / 20 \\
\text { Unemployment } 12 \mathrm{~m} \text { post-DBS: } \\
12 / 20\end{array}$ & {$[20]$} \\
\hline Holtzheimer (2012) & 17 & 10,7 & 42.0 & 22 & NM & 24 & $\begin{array}{l}92 \% \text { response } / 58 \% \\
\text { remission }\end{array}$ & $\begin{array}{l}\text { GAF: Baseline (17 pts): } 33.9(1.7) ; \\
2 \text { years post-DBS: } 78.7(4.1)\end{array}$ & [13] \\
\hline Malone Jr (2008) & 15 & 11,4 & 46.3 & 21.0 & NM & 48 & $\begin{array}{l}53 \% \text { response } / 40 \% \\
\text { remission }\end{array}$ & $\begin{array}{l}\text { GAF: Baseline } 43.4 \text { (2.8), last FU: } \\
61.8(13.1)\end{array}$ & [22] \\
\hline Schlaepfer (2013) & 7 & 3,4 & 42.6 & 7.6 & NM & 8 & $\begin{array}{l}6 \text { pts responders ( } 4 \\
\text { remitters) }\end{array}$ & $\begin{array}{l}\text { GAF: Baseline: } 42.8 \text { (SD 11), } \\
\text { post-DBS: } 61 \text { (SD 8.9) }\end{array}$ & [38] \\
\hline Bewernick (2010) & 10 & 4,6 & 48.6 & 17 & NM & 24 & $50 \%$ response & NM & {$[4]$} \\
\hline Puigdemont (2012) & 8 & 6,2 & 47.4 & 22.5 & NM & 12 & $\begin{array}{l}62.5 \% \text { response } / 50 \% \\
\text { remission }\end{array}$ & NM & [30] \\
\hline
\end{tabular}

m: male, f: female, NM: Not Mentioned, DBS: Deep brain stimulation, HDRS: Hamilton Depression Rating Scale, GAF: Global Assessment of Functioning, FU: Follow-up, m: months, y: years, SF-36: 36-item Short-Form Health Survey Questionnaire (SF-36), *Kennedy et al. 20II patients reported previously in Lozano et al. 2008

were used across studies. Further, the social impact of DBS was not uniformly reported for each patient within the same study; the authors detailed social outcomes mainly for patients where a difference in social behavior after DBS was observed. Therefore, we provided alongside the quantitative data verbatim the comments of the authors as to social functioning, so that the reader can form his own opinion.

Gilles de la Tourette

Eleven GTS studies were included [Table 1]. For the GTS group the mean age of patients was 28.1 years (SD 7.0 ), with a mean disease duration of 18.5 years (SD 7.6). The mean sample-size was 6.3 participants (SD 5.7) per study with a mean follow-up of 27 months (SD 27.7).

\section{Obsessive compulsive disorder}

13 OCD studies were included [Table 2]. The mean age of the OCD group was 38.3 years (SD 7.3). The mean sample size was 7.5 participants (SD 5.6) per study with a mean disease duration of 21.9 years (SD 7.7) and a mean follow-up of 19.6 months (SD 12.5).

Treatment resistant depression

Eight TRD studies were included [Table 3]. The TRD group had a mean age of 45.8 years (SD 2.7) and a mean disease duration of 18.7 years (SD 5.0). The mean sample sizes were 12.2 participants (SD 6.9) per study with a mean follow-up of 23.5 months (SD 13.4).

\section{Deep brain stimulation and social functioning}

Deep brain stimulation and social functioning in Gilles de la Tourette's syndrome

In a cohort of 17 patients Sachdev et al. ${ }^{[34]}$ noted that patients improved on all secondary measures. The authors wrote, "The wide ranging impact of TS on sufferers is well known, and although almost all our patients continued to display clinically relevant symptomatology, it is notable that the degree of improvement noted with DBS in these patients leads to significant gains in their day to day lives. Modest gains noted on symptom rating scores, often translate into greater functional gains, reflective of the high pretreatment severity of illness in such DBS cohorts. This is reflected more accurately in the improvements noted in the quality of life, and functional status ratings of this cohort for responders and the majority of non-responders alike."

Dehning et al. ${ }^{[8]}$ wrote, "Although at first view it appears self-evident that an improvement in symptomatic outcome will be accompanied by an improvement in functional outcome, in other psychiatric disorders symptomatic improvement often leaves persistent impairment in social functioning. Our data suggest that once DBS-induced remission is achieved in TS patients, the patients remain in remission in the long-term and thus can regain social functioning, including building a partnership and findings a regular employment."

The results of a 2-year follow-up on 15 patients were published by Porta et al. in 2009. ${ }^{[29]}$ DBS led to a $52 \%$ tic reduction on the Yale Global Tic Severity Scale (YGTSS) and to a $46 \%$ percentage change on the Yale Brown Obsessive Compulsive Scale (YBOCS). The mean Subjective Social Impairment-Visual Analog Scale (SSI-VAS) decreased postoperatively from 8.4 to 5.8. The authors reported, "The subjective perception of social impairment improved in 14 of 15 patients."

In 2009, this same group from Milan used nucleus accumbens DBS in four patients, who had failed to respond to thalamic or pallidal DBS. ${ }^{[39]}$ A tic reduction of $65 \%$ on the YGTSS was observed. For one patient, the 
authors observed, "He had many years which included difficulty in integrating into society, and he had many admissions to neurologic and psychiatric wards as a result of highly aggressive behavioral outbursts with multiple complex motor tics." After DBS "the patient was able to reintegrate into society, and was able to independently operate a car. His drug therapy was discontinued, and he maintained an ability to stay gainfully employed."

Welter et al. ${ }^{[44]}$ commented on an important tic reduction with pallidal and thalamic stimulation, while motor symptoms reoccurred during sham stimulation in three patients with a mean age of 32 years and a mean disease duration of 23 years. The patients presented multiple comorbidities, such as major depressive disorder (MDD), self-injury behavior (SIB), borderline-personality disorder (BPD), and generalized anxiety disorder (GAD). One patient returned 2 years after DBS to full-time work and began interpersonal psychotherapy, which enabled an improvement in interpersonal relationships. The second patient "did not recover his professional activity, while the third patient began ( 4 months after the end of the protocol) a professional educational retraining program."

A $76 \%$ tic reduction on the YGTSS and to a circa $70 \%$ change on the YBOCS in a 16-year-old male patient was recorded by Shahed et al. ${ }^{[40]}$ The patient had several comorbidities, such as OCD, attention deficit hyperactivity disorder (ADHD), coprolalia, and depression. The patient was academically and socially impaired before DBS. After DBS a "mild social introversion and withdrawal remained." The authors concluded that "the persistent social avoidance may have resulted from learned/reinforced presurgical behavior patterns."

Lee et al. ${ }^{[19]}$ observed in one 31 -year-old patient with a disease duration of 24 years, an important tic reduction following DBS. "Our patient was unemployed because of tics before the surgery. With improvement in his tics, he managed to find a job about a year after the surgery."

Zekaj et al. ${ }^{[45]}$ commented on an interesting case of a young Tourette syndrome (TS) patient treated with DBS at the age of 17 . The patient was followed up for 96 months. As the patient showed a stable clinical picture in off-condition for 2 years the whole DBS device was removed. "Before DBS, our patient was not able to confront the challenges of school and had to leave without qualification. After DBS he had an optimal professional formation and social insertion in the most crucial period of his young adult life." The authors proposed to consider DBS in TS as a "bridging therapy" to pass successfully the difficult period of a young adult life.

Deep brain stimulation and social functioning in obsessive compulsive disorder

Greenberg et al. ${ }^{[12]}$ reported on 10 OCD patients with a mean age of 35 years and a mean disease duration of 23 years. From the 10 included patients eight were followed up, one died 9 months after DBS (cancer), and one was followed up to 24 months with a $35 \%$ YBOCS change at latest follow-up. The Global Assessment of Functioning (GAF) increased from a mean 37 (SD 1.5) pre-DBS to 54 (SD 2.5) post-DBS. "No patient was working or in school before DBS; six were during chronic stimulation. Ability to perform activity of daily livings (ADLs) independently was markedly impaired in seven patients at baseline; this was true of one patient during DBS. No patient lived independently before DBS, whereas six did so afterwards. With the exception of the patient who died owing to recurrent breast cancer 9 months after implantation, social engagement improved in eight of nine patients, to varying degrees ranging from greater social contact to becoming engaged to marry."

Jiménez et al. ${ }^{[16]}$ noted in six OCD patients with a mean disease duration of 16 years that "during the stimulation period, all patients improved their relationships with their family and social environment. To date, two of the patients are employed."

Chabardès et al. ${ }^{[6]}$ treated four OCD patients with DBS. The resulted improvement allowed "a professional reintegration perspective and improving his social and family function."

Roh et al. ${ }^{[33]}$ followed-up for 24 months four patients with OCD and observed "individual interviews represent a change from serious impairment in social, occupational, or school functioning to generally normal function and having some social relationships."

Abelson et al. ${ }^{[1]}$ reported in one out of four patients with multiple associated comorbidities treated with DBS an initial positive impact on social outcome. The patient "returned to work for the first time in over a year. However, 2 months later, she left the new job because of intensifying depression and stress, and she committed suicide shortly thereafter. She left a note stating that her OCD was still improved and that her suicide was due to depression and unrelated to the study."

Deep brain stimulation and social functioning in treatment resistant depression

Kennedy et al. ${ }^{[18]}$ published the follow-up of 20 patients previously reported by Lozano et al. (2008) and Mayberg et al. (2005). "The rate of employment at the time of DBS surgery was $10 \%$. The rate increased to $50 \%$ by year 1 and onward. Three patients also began doing volunteer work, resulting in $65 \%$ of patients being engaged in work-related activities. Those who responded to treatment were more likely to return to work $(90.9 \%$ of those who responded, compared with $33.3 \%$ of those who did not, $P<0.05$; odds ratio $=20.95$; $\mathrm{CI}=1.7-238.6)$."

Lozano et al. ${ }^{[20]}$ followed-up for 12 months 20 patients with refractory depression. A 55\% response rate was 
observed and $35 \%$ of patients remitted. Eighteen out of the 20 patients were unemployed prior to DBS while this number 1 year post-DBS dropped to 12. "Six of 17 patients who were not working due to their illness at enrolment returned to employment after being unemployed for 2-7 years, indicating that DBS led to significant social reintegration."

Holtzheimer et al. ${ }^{[13]}$ published interesting results on 17 patients with a mean age of 42 years and a mean disease duration of 22 followed-up for 2 years. DBS led to a $92 \%$ response rate with a $58 \%$ remission rate. The GAF scale improved in all patients, suggesting that the treatments had also beneficial effects on social functioning [GAF: Baseline (17 patients): 33.9 (SD 1.7); 2 years post-DBS: 78.7 (4.1)]. Fourteen out of the 17 patients were unable to work prior to DBS. Regrettably no mentioning as to their working capacity in the postoperative setting was made; the GAF rates on a scale between 0 and 100, with lower scores reflecting worse status the psychological, social, and occupational functioning.

Bewernick et al. ${ }^{[4]}$ published the results on 10 patients with a response rate of $50 \%$ response following DBS. "Fifty percent of patients had never reached remission status since first diagnosis and all were retired from work due to depression." With respect to the DBS treatment response they stated, "Although the effect varied between patients, substantial positive changes in clinical symptoms and social life (e.g., returning to work part time, starting a new hobby, establishing a daily structure, and making new acquaintance) were observed in all patients."

Puigdemont et al. ${ }^{[30]}$ followed-up for 1 year eight patients with a mean age of 47 years and a mean disease duration of 23 years. A mean $63 \%$ response rate was observed. 50\% of patients remitted. The authors wrote: "At the time of writing the majority of patients have recovered, or even started leisure activities and social relationships, after having been inactive due to their depressive illness for several years prior to intervention. Additionally, two patients no longer require daily support. These are indicators that DBS would also enhance the psychosocial functioning."

\section{DISCUSSION}

The reviewed literature showed a significant variability in many factors including number of patients, mean age, comorbidities, disease duration, follow-up periods, and evaluating scales. Analyzing in a systematic and organized manner the available data allowed, however, despite the aforementioned encountered limitations, to appreciate certain patterns of the impact of DBS on social functioning.

Based on the available literature, DBS in refractory psychiatric disorders seems to have the potential to improve social functioning.
The modern era of DBS has made significant advances in treating refractory psychiatric respect the beginnings of psychosurgery. ${ }^{[25,35]}$ Several authors specified that patients who were unable to work before DBS were able to work after $\mathrm{DBS}^{[1,18-20,30,38,44,45]}$ and improved overall social functioning. Many of these patients were severely disabled for many years by the disease (often associated with equally or even more disabling comorbidities) displaying severe social maladjustment (at interpersonal and at professional level). As a result, reported improvement of social functioning in these cohorts may be of great clinical relevance.

However, we cannot make definitive conclusions on the effects of DBS on social functioning based on the current data. The positive results have to be interpreted with great caution. We had to exclude a large number of patients treated with DBS for psychiatric disorders, approximately 250, from our study since no data on social functioning were available. Within this context, one has to be bear in mind that authors may have avoided to report negative or neutral social outcomes, potentially leading to a selection bias in our considerations. In addition, sample sizes were too small (mean 8.3 participants per study, SD 3.2) to generalize findings. Studies focused more on symptom severity reduction than on social functioning. Data gathering on social impact was based on qualitative as quantitative approaches rendering a meaningful comparison of results between studies difficult. The social functioning showed also heterogeneity within the same study not allowing an analysis of different outcomes within the same study.

The data on GTS patients may be particularly difficult to interpret. Contrary to DBS for motor diseases in DBS for psychiatric disorders, targets are multiple. In GTS, the target choice is particularly complicated and heterogeneous given the great phenotypic variability of GTS. ${ }^{[28]}$ Dehning et al. ${ }^{[8]}$ write, "unlike in the 'classical' movement disorders, there does not seem to be 'one' target for DBS in TS: selected patients might respond to selected targets." Given these methodological inconsistency and the aforementioned limitations in DBS reporting ${ }^{[36]}$ our presented data does not allow to individuate any target that leads to more improvement in social functioning. Moreover, the studies in GTS had relatively short follow-up assessments (the mean follow-up period for the 236 included patients in our study was only 23.6 months, SD 3.5).

To fully evaluate the risks and benefits, including social functioning, of DBS in psychiatric disorders, several factors have to be systematically assessed: Severity of the treated patients refractory to any conventional psychiatric treatment, the natural disease course, the severe side effects of conventional treatment, the symptomatic improvement, and the social impact of DBS.

Social outcomes are particularly important in the assessment of therapeutic intervention in psychiatry. The 
World Health Organization (1948) defines health as "a state of complete physical, mental and social well-being and not merely the absence of disease or infirmity." $[11]$ In addition, social deficits are frequently core aspects or important consequences of psychiatric conditions.

The assessment of social outcomes is not trivial. Unfortunately, there is no standard assessment. Social functioning includes multiple roles of an individual such as personal, social and professional interactions; it relates consequently directly to the quality of life of a participant. ${ }^{[32]}$ These aspects should be considered when assessing social outcomes.

To evaluate more exhaustively the social outcomes of DBS, we recommend the use of the GAF and the Social Adjustment Scale. ${ }^{[43]}$ It is important to be aware that symptom-severity improvement may not always translate into improved social functioning. The reasons for this lack of direct relationship are multiple. For example, social functioning does not solely relate to a participant's physical and mental well-being, but equally to variables beyond the influence of medical treatment.

\section{CONCLUSION}

The current data on the social effects of DBS in psychiatric conditions is incomplete and inconclusive. However, from the available data DBS seems to have the potential to improve social functioning. Larger, multicentered trials are needed to increase statistical power, with systematic assessment of social outcomes along with longer follow-ups and closer postoperative surveillance, to evaluate more accurately the impact of DBS on social functioning.

\section{Financial support and sponsorship}

Nil.

\section{Conflicts of interest}

There are no conflicts of interest.

\section{REFERENCES}

I. Abelson JL, Curtis GC, Sagher O, Albucher RC, Harrigan M, Taylor SF, et al. Deep brain stimulation for refractory obsessive-compulsive disorder. Biol Psychiatry 2005;57:510-6.

2. Aouizerate B, Cuny E, Martin-Guehl C, Guehl D, Amieva H, Benazzouz A, et al. Deep brain stimulation of the ventral caudate nucleus in the treatment of obsessive-compulsive disorder and major depression. Case report. J Neurosurg 2004; 101:682-6.

3. Benabid AL, Pollak P, Gervason C, Hoffmann D, Gao DM, Hommel M, et al. Long-term suppression of tremor by chronic stimulation of the ventral intermediate thalamic nucleus. Lancet 1991;337:403-6.

4. Bewernick BH, Hurlemann R, Matusch A, Kayser S, Grubert C, Hadrysiewicz B, et al. Nucleus accumbens deep brain stimulation decreases ratings of depression and anxiety in treatment-resistant depression. Biol Psychiatry 2010;67:110-6.

5. Cannon E, Silburn P, Coyne T, O'Maley K, Crawford JD, Sachdev PS. Deep brain stimulation of anteromedial globus pallidus interna for severe Tourette's syndrome. Am J Psychiatry 2012;169:860-6.
6. Chabardes S, Polosan M, Krack P, Bastin J, Krainik A, David O, et al. Deep brain stimulation for obsessive-compulsive disorder: Subthalamic nucleus target. World Neurosurg 2013;80:S3I el-8.

7. De Silva MJ, Cooper S, Li HL, Lund C, Patel V. Effect of psychosocial interventions on social functioning in depression and schizophrenia: Meta-analysis. Br J Psychiatry 2013;202:253-60.

8. Dehning S, Leitner B, Schennach R, Muller N, Botzel K, Obermeier M, et al. Functional outcome and quality of life in Tourette's syndrome after deep brain stimulation of the posteroventrolateral globus pallidus internus: Long-term follow-up. World J Biol Psychiatry 20I4;15:66-75.

9. Denys D, Mantione M, Figee M, van den Munckhof P, Koerselman F, Westenberg $\mathrm{H}$, et al. Deep brain stimulation of the nucleus accumbens for treatment-refractory obsessive-compulsive disorder. Arch Gen Psychiatry 2010;67:106I-8.

10. Franzini A, Messina G, Gambini O, Muffatti R, Scarone S, Cordella R, et al. Deep-brain stimulation of the nucleus accumbens in obsessive compulsive disorder: Clinical, surgical and electrophysiological considerations in two consecutive patients. Neurol Sci 2010;31:353-9.

II. Grad FP. The Preamble of the Constitution of the World Health Organization. Bull World Health Organ 2002;80:98I-4.

12. Greenberg BD, Malone DA, Friehs GM, Rezai AR, Kubu CS, Malloy PF, et al. Three-year outcomes in deep brain stimulation for highly resistant obsessive-compulsive disorder. Neuropsychopharmacology 2006;3I:2384-93.

13. Holtzheimer PE, $3^{\text {rd }}$, Meeks TW, Kelley ME, Mufti M, Young R, McWhorter K, et al. A double blind, placebo-controlled pilot study of galantamine augmentation of antidepressant treatment in older adults with major depression. Int J Geriatr Psychiatry 2008;23:625-3I.

14. Huff W, Lenartz D, Schormann M, Lee SH, Kuhn J, Koulousakis A, et al. Unilateral deep brain stimulation of the nucleus accumbens in patients with treatment-resistant obsessive-compulsive disorder: Outcomes after one year. Clin Neurol Neurosurg 20 I 0; I I 2: 137-43.

15. Huys D, Bartsch C, Koester P, Lenartz D, Maarouf M, Daumann J, et al. Motor Improvement and Emotional Stabilization in Patients With Tourette Syndrome After Deep Brain Stimulation of the Ventral Anterior and Ventrolateral Motor Part of the Thalamus. Biol Psychiatry 2016;79:392-40I.

16. Jiménez F, Nicolini H, Lozano AM, Piedimonte F, Salin R, Velasco F. Electrical stimulation of the inferior thalamic peduncle in the treatment of major depression and obsessive compulsive disorders. World Neurosurg 20। 3;80:S30 el 7-25.

17. Kaido T, Otsuki T, Kaneko Y, Takahashi A, Omori M, Okamoto T. Deep brain stimulation for Tourette syndrome: A prospective pilot study in Japan. Neuromodulation 201 I; 14:123-8; discussion 9.

18. Kennedy SH, Giacobbe P, Rizvi SJ, Placenza FM, Nishikawa Y, Mayberg HS, et al. Deep brain stimulation for treatment-resistant depression: Follow-up after 3 to 6 years. Am J Psychiatry 201 I; 168:502-10.

19. Lee MW, Au-Yeung MM, Hung KN, Wong CK. Deep brain stimulation in a Chinese Tourette's syndrome patient. Hong Kong Med J 201 I; 17:147-50.

20. Lozano AM, Mayberg HS, Giacobbe P, Hamani C, Craddock RC, Kennedy SH. Subcallosal cingulate gyrus deep brain stimulation for treatment-resistant depression. Biol Psychiatry 2008;64:46I-7.

21. Mallet L, Polosan M, Jaafari N, Baup N, Welter ML, Fontaine D, et al. Subthalamic nucleus stimulation in severe obsessive-compulsive disorder. N Engl J Med 2008;359:2 I 2I-34.

22. Malone DA, Jr., Dougherty DD, Rezai AR, Carpenter LL, Friehs GM, Eskandar EN, et al. Deep brain stimulation of the ventral capsule/ventral striatum for treatment-resistant depression. Biol Psychiatry 2009;65:267-75.

23. Mayberg HS, Lozano AM, Voon V, McNeely HE, Seminowicz D, Hamani C, et al. Deep brain stimulation for treatment-resistant depression. Neuron 2005;45:65I-60.

24. Nuttin B, Cosyns P, Demeulemeester H, Gybels J, Meyerson B. Electrical stimulation in anterior limbs of internal capsules in patients with obsessive-compulsive disorder. Lancet 1999;354:1526.

25. Ogren K, Sandlund M. Lobotomy at a state mental hospital in Sweden. A survey of patients operated on during the period 1947-1958. Nord J Psychiatry 2007;61:355-62.

26. Ooms P, Mantione M, Figee M, Schuurman PR, van den Munckhof P, Denys D. Deep brain stimulation for obsessive-compulsive disorders: Long-term analysis of quality of life. J Neurol Neurosurg Psychiatry 2014;85:153-8.

27. Patel V, Simon G, Chowdhary N, Kaaya S, Araya R. Packages of care for 
depression in low- and middle-income countries. PLoS Med 2009;6:el 000159.

28. Porta M, Saleh C, Zekaj E, Zanaboni Dina C, Bona AR, Servello D. Why so many deep brain stimulation targets in Tourette's syndrome? Toward a broadening of the definition of the syndrome. J Neural Transm (Vienna) 2016;123:785-90.

29. Porta M, Sassi M, Ali F, Cavanna AE, Servello D. Neurosurgical treatment for Gilles de la Tourette syndrome: The Italian perspective. J Psychosom Res 2009;67:585-90.

30. Puigdemont D, Perez-Egea R, Portella MJ, Molet J, de Diego-Adelino J, Gironell A, et al. Deep brain stimulation of the subcallosal cingulate gyrus: Further evidence in treatment-resistant major depression. Int J Neuropsychopharmacol 2012;15:121-33.

31. RamirezA, Ekselius L, Ramklint M.Axis V - Global Assessment of Functioning scale (GAF), further evaluation of the self-report version. Eur Psychiatry 2008;23:575-9

32. Renner F, Cuijpers P, Huibers MJ. The effect of psychotherapy for depression on improvements in social functioning: A meta-analysis. Psychol Med 20|4;44:29|3-26.

33. Roh D, Chang WS, Chang JW, Kim CH. Long-term follow-up of deep brain stimulation for refractory obsessive-compulsive disorder. Psychiatry Res 2012;200: 1067-70.

34. Sachdev PS, Mohan A, Cannon E, Crawford JD, Silberstein P, Cook R, et al. Deep brain stimulation of the antero-medial globus pallidus interna for Tourette syndrome. PLoS One 2014;9:el 04926.

35. Saleh C, Fontaine D. Deep brain stimulation for psychiatric diseases: What are the risks? Curr Psychiatry Rep 2015;17:33.

36. Saleh C, Gale JT, Eskandar E. The need for a multifactorial approach to raise the standard in deep brain stimulation reporting. Neuromodulation 20I I; 14:183-4.
37. Schaub D, Brune M, Jaspen E, Pajonk FG, Bierhoff HW, Juckel G. The illness and everyday living: Close interplay of psychopathological syndromes and psychosocial functioning in chronic schizophrenia. Eur Arch Psychiatry Clin Neurosci 2011;261:85-93.

38. Schlaepfer TE, Bewernick BH, Kayser S, Madler B, Coenen VA. Rapid effects of deep brain stimulation for treatment-resistant major depression. Biol Psychiatry 2013;73:1204-12.

39. Servello D, Sassi M, Brambilla A, Porta M, Haq I, Foote KD, et al. De novo and rescue DBS leads for refractory Tourette syndrome patients with severe comorbid OCD: A multiple case report. J Neurol 2009;256:1533-9.

40. Shahed J, Poysky J, Kenney C, Simpson R, Jankovic J. GPi deep brain stimulation for Tourette syndrome improves tics and psychiatric comorbidities. Neurology 2007;68:159-60.

4I. Tsai HC, Chang CH, Pan Jl, Hsieh HJ, Tsai ST, Hung HY, et al. Pilot study of deep brain stimulation in refractory obsessive-compulsive disorder ethnic Chinese patients. Psychiatry Clin Neurosci 2012;66:303-I2.

42. Vandewalle V, van der Linden C, Groenewegen HJ, Caemaert J. Stereotactic treatment of Gilles de la Tourette syndrome by high frequency stimulation of thalamus. Lancet 1999;353:724.

43. Weissman MM, Prusoff BA, Thompson WD, Harding PS, Myers JK. Social adjustment by self-report in a community sample and in psychiatric outpatients. J Nerv Ment Dis 1978;166:317-26.

44. Welter ML, Mallet L, Houeto JL, Karachi C, Czernecki V, Cornu P, et al. Internal pallidal and thalamic stimulation in patients with Tourette syndrome. Arch Neurol 2008;65:952-7.

45. Zekaj E, Saleh C, Porta M, Servello D. Temporary deep brain stimulation in Gilles de la Tourette syndrome: A feasible approach? Surg Neurol Int 20I5;6:122.

\section{Commentary}

We recommend our readers to pay attention to this excellent and organized review of the literature on the social impact of deep brain stimulation (DBS) for diverse applications in psychiatric disorders. The importance of this article is immense, as it criticizes the literature on the most important role of any therapy. Does DBS really impact on patients' quality of life?

DBS will only be valuable as a therapy if it is scientifically shown that it impacts on the patients' quality of life, mostly bring the psychiatric patients to the main flow of society as productive citizens, or at least less dependent as possible. Although quantitative data are scarce, the positivity of the comments observed by the majority of the authors make DBS a valuable therapy for the scientific community to spend time sorting its real value. Those interested on behavior surgery, the discredit in the past psychosurgery, have to take the task of evaluating with critical scales reflecting adjustment of patients in their social environment in a strict scientific fashion.

Antonio A.F. De Salles

Professor Emeritus of Neurosurgery - UCLA, Departments of Neurosurgery and Radiation Oncology. Head, HCor Neuroscience E-mail: a.desalles@yahoo.com 